\title{
Skin and bone integrated prosthetic pylon: A pilot animal study
}

\author{
Mark Pitkin, PhD; ${ }^{1-2 *}$ Grigory Raykhtsaum; ${ }^{2}$ Oleg V. Galibin, MD, PhD; ${ }^{3}$ Mikhail V. Protasov, MD; ${ }^{3}$ \\ Julie V. Chihovskaya, MD; ${ }^{3}$ Irina G. Belyaeva, $\mathbf{M D}, \mathbf{P h D}^{3}$ \\ ${ }^{1}$ Department of Physical Medicine and Rehabilitation, Tufts University School of Medicine, Boston, MA; \\ ${ }^{2}$ Poly-Orth International, Sharon, MA; ${ }^{3}$ Department of Experimental Medicine, I. P. Pavlov State Medical \\ University, St. Petersburg, Russia
}

\begin{abstract}
Direct skeletal attachment of limb prostheses is a viable alternative to traditional techniques that are based on a socket-residuum interface. Direct skeletal attachment may be a better or even the only method for patients with a very short residuum and high soft-tissue volume. The problem of integrating the prosthetic pylon with residual skin during direct skeletal attachment of a limb prosthesis has not been solved, and the use of a completely porous prosthetic pylon has not been the subject of focused, systematic research. In this in vivo study, we investigated cell (osteocyte, fibroblast, and keratinocyte) adhesion and penetration into the pores of a titanium pylon implanted in Wistar rats. The porous titanium pylon was implanted in the bone of the thigh residua of four rats. Electronic scanning and morphological analysis demonstrated integration of the pylon with the surrounding skin. These findings support the possibility of developing a natural barrier against the infection associated with direct skeletal attachment of limb prostheses.
\end{abstract}

Key words: amputation, animal model, cell adhesion, osseointegration, porous titanium, prosthetic pylon, rehabilitation, residuum, skin infection, skin ingrowth.

\section{INTRODUCTION}

The technology of direct skeletal attachment of limb prostheses, called osseointegration, was introduced in the 1990s [1]. In osseointegration, a titanium fixture is inserted into the bone remnant of the residuum and a skin-penetrating abutment is used for attaching the prosthesis. Despite the promising integration of a titanium implant with residual bone, the problem of the device- skin interface where the implant penetrates the residual limb remains unsolved [2]. Attempts at optimizing the roughness of the abutment to achieve a reliable deviceskin interface were unsuccessful [3], and ongoing subject trials use abutments with a smooth surface [4]. Without a reliable device-skin interface, the surrounding skin can move freely along the device, which causes the formation of a layer of pus between the skin and titanium fixture (Figure 1). A study on 11 patients who underwent this procedure in England revealed 46 episodes of superficial infection in 6 patients and deep infection in 1 [4].

Infection on percutaneous devices in dentistry, joint replacement, and vascular surgery has been the subject of intense study. Implants may be colonized by airborne, skin, and/or surgeon-related bacteria during surgery despite use of closely monitored surgical techniques. After successful attachment on the biomaterial surface, bacteria multiply and form a "biofilm" community, which makes them much more resistant to antibiotic therapy and host immunity [5].

Strategies for reducing skin infection in direct skeletal attachment of limb prostheses include surface and shape modification of the percutaneous device [6-8], the addition

\footnotetext{
Abbreviations: ASTM = American Society for Testing Materials, $\mathrm{NIH}=$ National Institutes of Health, UV = ultraviolet.

* Address all correspondence to Mark Pitkin, PhD; Poly-Orth International, 26 Mallard Drive, Sharon, MA 02067; 781-7844434; fax: 781-344-0128. Email: mpitkin@tufts-nemc.org DOI: 10.1682/JRRD.2005.05.0160
} 
of antimicrobials to the surface of the device, and chemical modifications, which reduce bacterial attachment [9]. Thus far, these strategies have been unsuccessful.

For reduced risk of infection in the abutment-skin area, we proposed the use of a porous titanium structure and conducted in vitro and in vivo pilot studies with porous titanium pellets [10-12]. The pellets met the following specifications: (1) titanium grade American Society for Testing Materials (ASTM) F-67 unalloyed titanium for surgical implants, (2) average sphere size of $450 \mu \mathrm{m}$, (3) porosity of 30 percent, (4) diameter of $1.6 \mathrm{~mm}$, and (5) thickness of $0.32 \mathrm{~cm}$. After sterilization, the pellets were seeded with human dermal fibroblasts and stromal cells of rabbit bone marrow and cultured for 7 days. The following pellet treatments were performed: (1) 1:1 mixture of collagen and histone, (2) histone, (3) collagen, and (4) nontreated (control). Human dermal fibroblasts were plated on the treated pellets in a concentration of $25 \times 104$ cells $/ \mathrm{mL}$ and cultured for 7 days. Dulbecco's Modified Eagle Medium with 10 percent fetal calf serum was used as the nutrient media. Scan and fluorescent microscopy were used for evaluating cell morphology. After 7 days, a 100 percent confluent monolayer of cells was found on and inside the pellets treated with histone, collagen, and the 1:1 mixture of histone and collagen. The treated and nontreated pellets were not significantly different, probably because of the short observation period (7 days). However, the cell spread and growth suggested that further integration of the titanium implant with the recipient's skin and bone tissues was possible.

In the in vivo pilot study, we implanted the porous titanium pellets in two male Wistar rats [12]. Under general anesthesia, a subcutaneous subfascial pocket was formed after the cutaneous incision. A porous titanium pellet was inserted and stitched to the pocket and aseptic dressing was applied. The observation period was 10 days. We used a rat with a modeled wound as the control animal. Microscopic tests of the tissues that covered the pellets were performed with light microscopy (hemotoxylin-eosin staining). The surface of the pellets was investigated via reflected ultraviolet (UV) and halogen light rays. The cells in the pores and on the titanium surface were detected by specific lighting in UV rays. The cell metabolic activity was quantitatively measured by nicotinamide adenine dinucleotide phosphate-hydrogen fluorescence in UV rays. A macroscopic investigation of the wound was performed and no signs of inflammation were detected in either rat. We concluded that the porous titanium implants could potentially act as scaffolds for the formation of a device-skin infection barrier.

The work presented in this article is the first to our knowledge to have developed a porous titanium prosthetic pylon [13] for direct skeletal attachment of leg prostheses following our feasibility study [12]. A porous titanium pylon was implanted in the bone of the thigh residua of four rats. Electronic scanning and morphological analysis demonstrated not only osseointegration but also integration of the pylon with the surrounding skin. The latter finding raises the possibility of developing a natural barrier against the infection associated with direct skeletal attachment of limb prostheses.

\section{MATERIALS AND METHODS}

\section{Titanium Pylons}

The experimental pylons that we used for direct skeletal attachment were cylindrical rods $40 \mathrm{~mm}$ in length and $2 \mathrm{~mm}$ in diameter. The pylons (ADMA Products, Inc, Hudson, Ohio) met the pellet specifications tested in our previous studies $[10,12]$. The titanium grade ASTM F-67 unalloyed titanium for surgical implants was used in the form of sintered spherical particles. The average size of the particles was $450 \mu \mathrm{m}$ and average porosity was 30 percent. In the control group, we used a solid titanium rod (Small Parts, Inc, Miami Lakes, Florida) with a $1.5 \mathrm{~mm}$ diameter.

\section{Animals and Surgery}

Adult male Wistar rats $(N=7$, weight $=225-250 \mathrm{~g}$, Ruppolovo Russian Academy of Medical Science, St. Petersburg, Russia) were handled in accordance with National Institutes of Health (NIH) Guide for the Care and Use of Laboratory Animals (NIH publication 85-23, Rev. 1985) and the instructions of the Panel on Euthanasia of the American Veterinary Medical Association. All procedures were performed in accordance with protocols approved by the Ethics Committee of the I. P. Pavlov State Medical University, St. Petersburg, Russia. An anesthetic solution containing sodium pentobarbital (40 mg/mL, Nembutal, Abbott Laboratories, Moscow, Russia) and diazepam (5 mg/mL, Roche Moscow, Ltd, Moscow, Russia) was injected intraperitoneally. Surgery was performed under sterile conditions. 


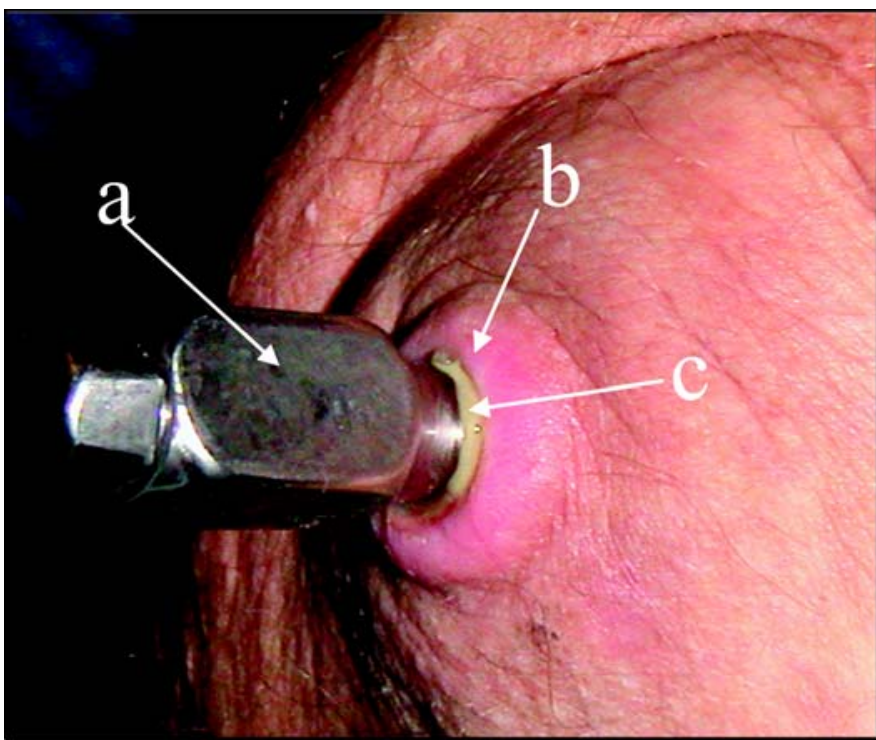

Figure 1.

(a) Solid titanium abutment penetrating the residuum skin. (b) Surrounding skin. (c) Layer of pus between skin and abutment.

\section{Experimental Group}

We amputated the lower-third of the rear thigh in four rats. The porous titanium pylon was implanted in the residuum. We performed a circular cut of the skin in the upper-third of the shin. The skin-fascia rag on the shin and lower- and middle-third of the thigh was separated. The vascular bundle was stitched and tied up in the middle-third of the thigh. We circularly cut the muscles at the level of the lower-third of the thigh. The capsule of the knee joint was cut and the disarticulation was made. We used Lyston forceps to split off the distal epiphysis of the femur. The marrow canal was trepanned and consecutively bored out with reamers (diameters $1 \mathrm{~mm}, 1.5 \mathrm{~mm}$, and $2.0 \mathrm{~mm}$ ). We implanted the porous titanium pylon in the marrow canal with the free end of the pylon positioned at the center of the operative zone (Figure 2).

\section{Control Group}

For the three control rats, we performed the amputation and implantation procedure as described for the experimental group. The only difference was that the control pylon was not porous but made of solid titanium.

Both groups were observed for 14 and 28 days. These observation periods were chosen for the following reasons: (1) by Day 14, acute inflammatory reactions and the wound-healing process should be complete and (2) by Day 28, chronic inflammatory reactions are expected.

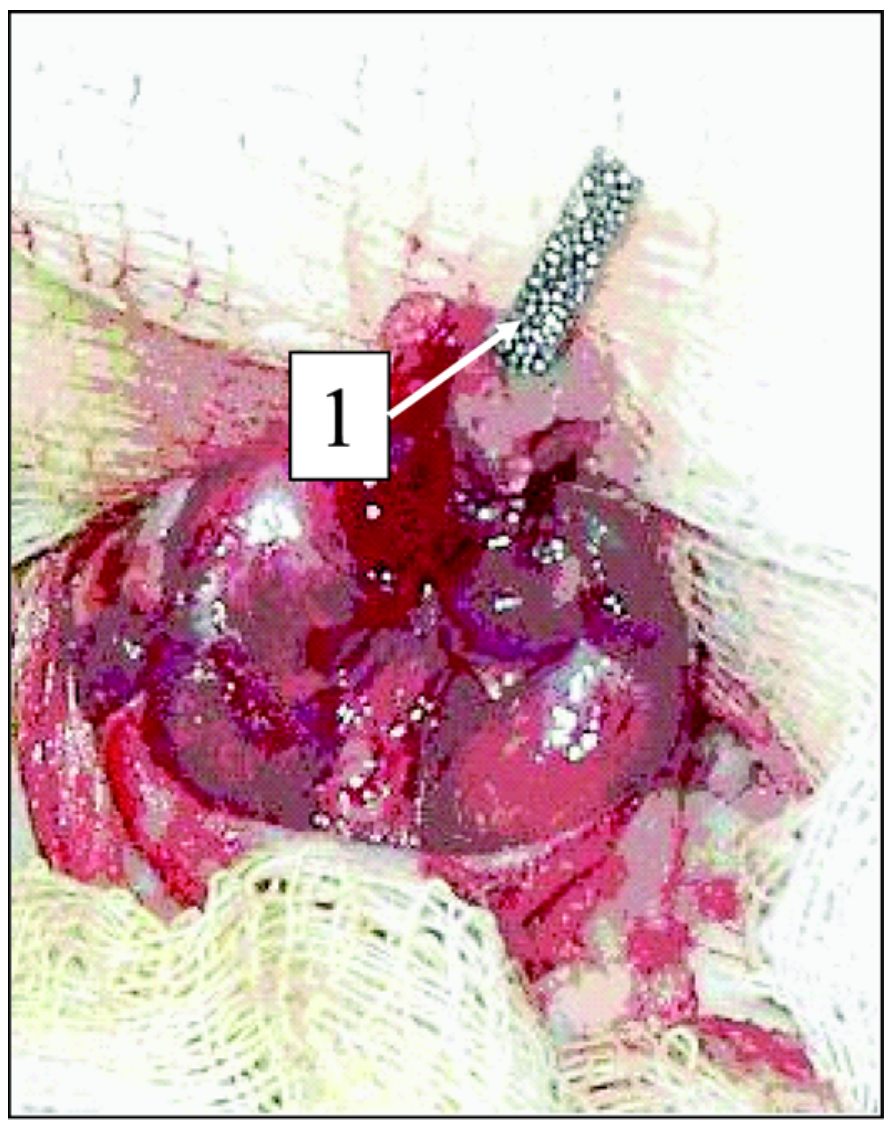

Figure 2.

Implantation of the experimental porous titanium pylon (designated by “ 1 ”) in marrow canal of Wistar rat thigh.

\section{Morphological Investigation}

Electronic scanning of the porous and solid titanium implants (surface and cross section) was performed with an electron scanning microscope (JEOL-USA, Inc, Peabody, Massachusetts). For morphological investigation of histological sections of surrounding tissues (hematoxylin-eosin and Van Gizon staining), we used a light microscope (Lumam-01M, LOMO PLC, St. Petersburg, Russia).

\section{RESULTS}

No rats from either the experimental or control group died. No signs of acute inflammation were observed by light microscopy analysis on Day 14 in either the experimental or control group. Also, the connective tissue capsules surrounding the pylons had not been formed.

On Day 28 after implantation (Figure 3), the implants were removed from the rats and investigated 
with electronic microscopy. The solid pylons were easily removed from the marrow canal without noticeable resistance. Electron scanning of the control samples demonstrated no cell or fiber adhesion to the surface of the solid pylon (Figure 4).

Extraction of the porous titanium pylons was made with noticeable resistance because of their stronger interface with the surrounding tissues. Electron scanning of

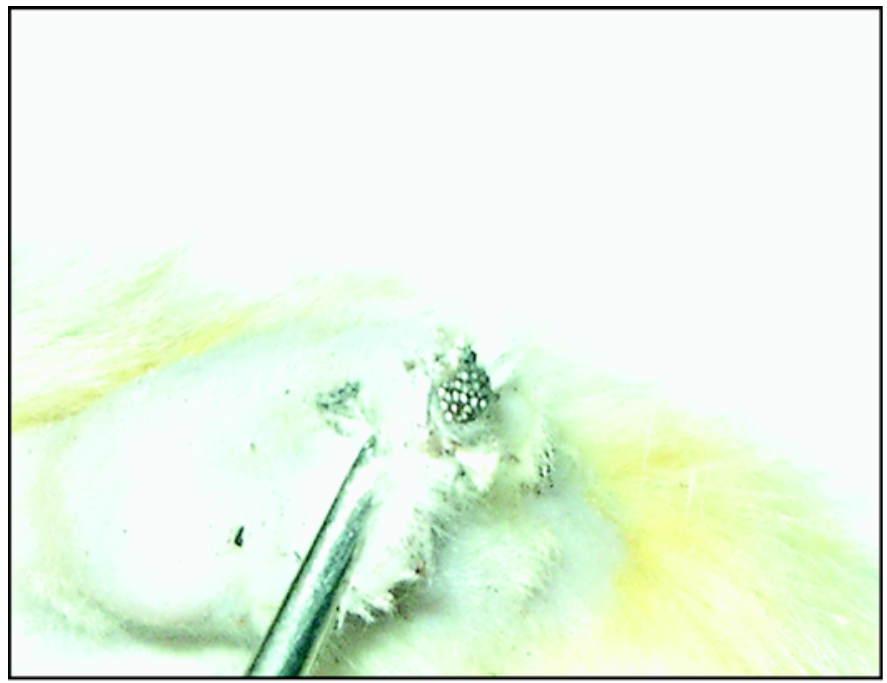

Figure 3.

Experimental porous titanium pylon 28 days after implantation.

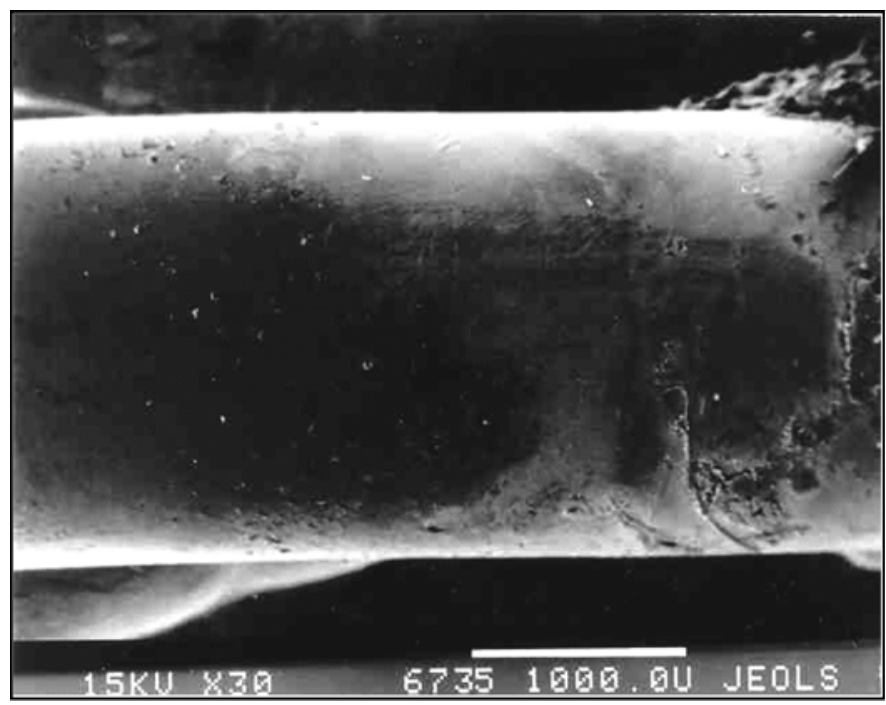

Figure 4.

Control solid titanium pylon 28 days after implantation. Image by electron scanning photomicrography (30×, JEOL-USA, Inc, Peabody, Massachusetts). Note smooth surface of metal and lack of cell adhesion. the cross section of the porous pylons where they contacted the surrounding skin demonstrated deep penetration of the cells (erythrocytes, lymphocytes, multiple fibroblast-like cells) inside the pores (Figures 5-6).

In the tissues surrounding the implants at the skin level and under the skin, no signs of inflammation were seen in the experimental group (Figure 7), while some abscess indicators were noted in the control group (Figure 8).

In the experimental group, we observed the development of fibrous tissues. Van Gizon staining causes fibrous tissues to absorb the red color, as shown in Figure 7.

Microscopic investigation of histological sections of surrounding tissues detected lymphoid infiltration in surrounding tissues in both rat groups. Lymphoid infiltration can be caused by immune rejection of a nonbiological material. Pronounced neutrophil infiltration (abscess formation) was also detected in two control rats (i.e., animals with solid pylon implantation) (Figure 8).

\section{DISCUSSION}

This pilot study demonstrated that the material used for the porous titanium pylon, in comparison with the solid titanium pylon, did not stimulate inflammatory rejection in the surrounding skin, muscle, or bone tissues.

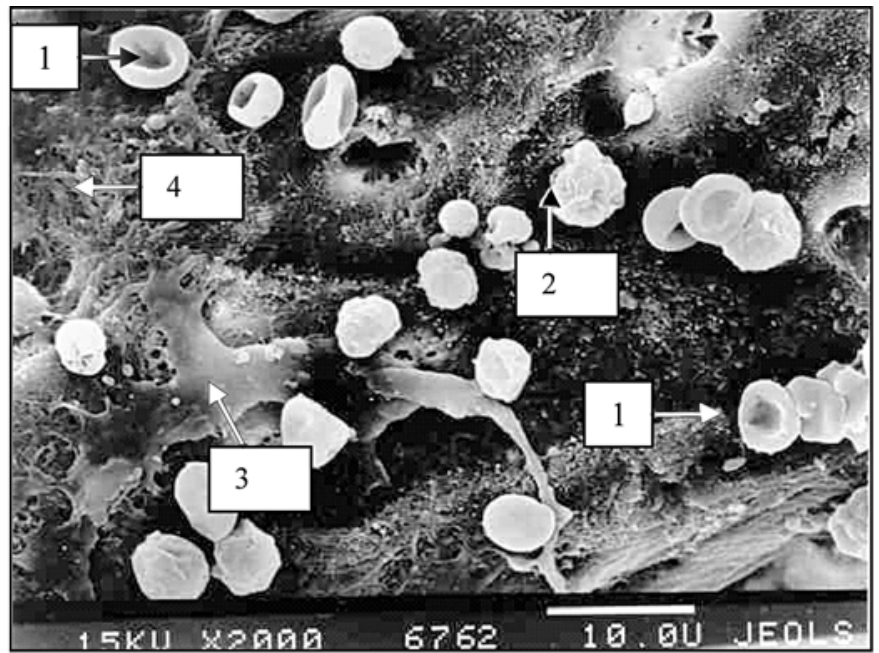

Figure 5.

Cross section of experimental porous titanium pylon 28 days after implantation. Image by electron scanning photomicrography (2000×, JEOL-USA, Inc, Peabody, Massachusetts). Note deep penetration of cells inside pores. 1 = erythrocyte, 2 = lymphoid cell, 3 = fibroblastlike cell, 4 = intercellular matrix on metal surface. 


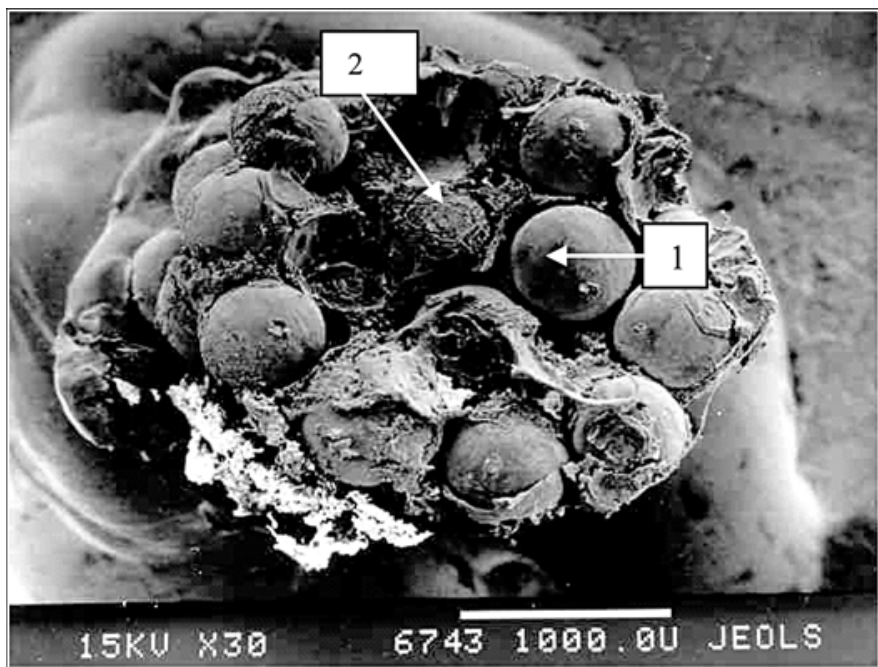

Figure 6.

Cross section at area of contact with skin of experimental porous titanium pylon 28 days after implantation. Electron scanning photomicrography (30×, JEOL-USA, Inc, Peabody, Massachusetts). 1 = titanium particles, 2 = penetration of cells and elements of intercellular matrix into pores.

After implantation of the porous pylon, cells and fibers, including erythrocyte lymphoid cells and fibroblast-like cells, penetrated the pores. Development of fibrous tissues around the porous implant is a necessary element of osseointegration [14]. Therefore, based on the current study, we suggest that the development of fibrous tissues around the porous pylon can potentially further the integration of bone and skin with the prosthetic device.

While these preliminary results suggest the potential for development of a skin barrier inside the porous pylon, more studies on sustainability of such a barrier are required. In future studies, we plan to investigate the following characteristics of cell-pylon interactions: cell adhesion, morphology, spreading, proliferation, and metabolism.

The physical nature of cell adhesion is associated with the electrostatic charges of a cell and the surface of a scaffold/matrix. Quantitatively, adhesion is determined by the ratio of the number of cells attached to the implant to the number of initially seeded cells. In the dynamic process of a cell's interface with the scaffold/matrix, force of attachment depends on the life cycle of the cell and reaches its minimum when the cell is dividing and migrating. As our preliminary study showed, when approximately 50 percent of cells become attached 1-hour postseeding, they are able to grow further on the scaffold/matrix and develop a distinct monolayer on the particles of the scaffold/matrix [11].

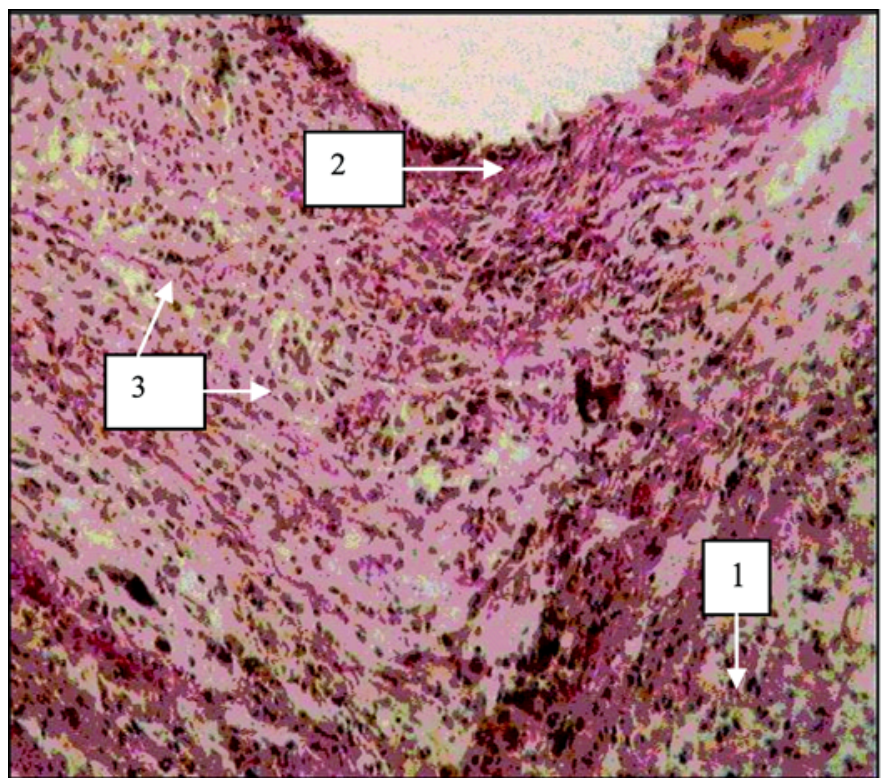

Figure 7.

Tissues surrounding experimental porous titanium pylon 28 days after implantation. Image by light microscopy (600×, Van Gizon staining). 1 = lymphoid infiltration, 2 = fibrous connective tissue capsule surrounding pylon, 3 = granulation.

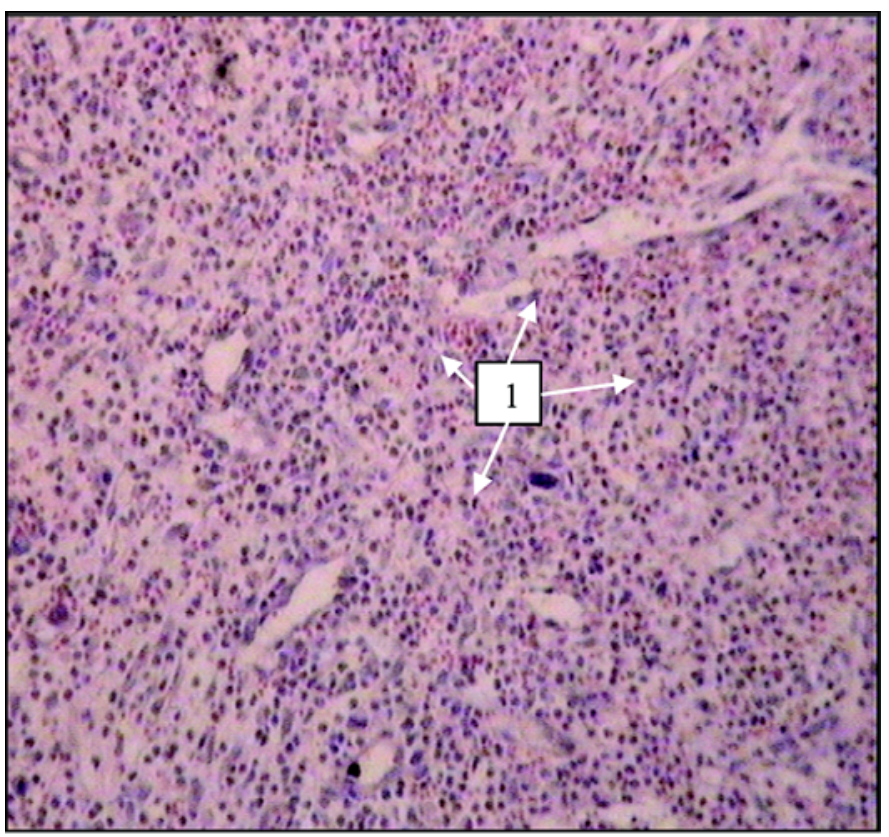

Figure 8.

Tissues surrounding control solid titanium implant 28 days after implantation. Neutrophil infiltration (designated by “ 1 ”) suggests formation of abscess. Image by light microscopy (600×, hematoxylineosin staining). 
Cell morphology will be determined by scanning microscopy. A cytoskeleton will be assessed by immunofluorescent staining with Rhodamine phalloidin. The morphology of the cells will be considered acceptable when the observed cells are not spherical but instead spread on the surface of the scaffold/matrix [15-19].

Cell proliferation will be estimated by the slopes of the corresponding cell-growth curve, which is a mathematical model of mammalian cell-growth kinetics. An early exponential cell-growth period is typically followed by a gradual slowdown in cell growth as the viable cell concentration reaches its maximum value because a key nutrient component depletes or a toxic metabolite accumulates [20]. The cell-growth conditions will be compared with the slopes of their corresponding cell-growth curves [3,21-23].

\section{CONCLUSIONS}

We preliminarily conclude that experimental porous titanium pylons provide an inviting environment for the surrounding tissues, including erythrocytes and lymphocytes. The presence of these blood cells suggests the possibility of blood vessel germination, which is necessary for development of a sustainable skin barrier inside the porous pylon.

\section{ACKNOWLEDGMENTS}

We are thankful to ADMA Products, Inc, Hudson, Ohio, for manufacturing the experimental porous pylons for the study. ADMA Products, Inc, did not have any involvement in the study design; data collection, analysis, or interpretation; and writing or submission of this article.

This material is the result of work supported with resources and the use of facilities at Poly-Orth International, Sharon, Massachusetts.

The authors have declared that no competing interests exist.

\section{REFERENCES}

1. Branemark R, Branemark PI, Rydevik B, Myers RR. Osseointegration in skeletal reconstruction and rehabilitation: A review. J Rehabil Res Dev. 2001;38(2):175-81. [PMID: 11392650]
2. Sullivan J, Uden M, Robinson KP, Sooriakumaran S. Rehabilitation of the trans-femoral amputee with an osseointegrated prosthesis: The United Kingdom experience. Prosthet Orthot Int. 2003;27(2):114-20. [PMID: 14571941]

3. Deligianni DD, Katsala ND, Koutsoukos PG, Missirlis YF. Effect of surface roughness of hydroxyapatite on human bone marrow cell adhesion, proliferation, differentiation and detachment strength. Biomaterials. 2001;22(1):87-96. [PMID: 11085388]

4. Sooriakumaran S, Robinson KP, Ward DA. Pattern of infection of transfemoral osseointegration. In: Proceedings of the 11th World Congress, International Society for Prosthetics \& Orthotics. 2004; Wanchai, Hong Kong; Hong Kong: ISPO; 2004. p. 252.

5. Gallo J, Kolar M, Novotny R, Rihakova P, Ticha VV. Pathogenesis of prosthesis-related infection. Biomed Pap Med Fac Univ Palacky Olomouc Czech Repub. 2003; 147(1):27-35. [PMID: 15034602]

6. Shin Y, Akao M. Tissue reactions to various percutaneous materials with different surface properties and structures. Artif Organs. 1997;21(9):995-1001. [PMID: 9288870]

7. Yu C, Harris GD. The LPD-II: a modified locked percutaneous device that permits safe subcutaneous access. ASAIO J. 2001;47(1):25-29. [PMID: 11199309]

8. Yu C, Harris GD, Sun Y. An alternative design of locked percutaneous device for skeletal extension through skin. Artif Organs. 2003;27(3):267-71. [PMID: 12662214]

9. Silverstein A, Donatucci CF. Bacterials biofilms and implantable prosthetic devices. Int J Impot Res. 2003; 15(Suppl 5):S150-54. [PMID: 14551596]

10. Pitkin M, Blinova MI, Yudintseva NV, Potokin IL, Raykhtsaum G, Pinaev GP. Skin and bone integrated prosthetic technology. I. Characterization and morphology of human cells cultivated on titanium implants of different structures [abstract]. In: Proceedings of the 9th Russian National Congress, People and Health. 2004 Nov 22-26; St. Petersburg, Russia; St. Petersburg: Russian National Congress; 2004. p. 217.

11. Blinova MI, Yudintseva NV, Kuhareva LV, Goryuhina OA, Potokin IL, Pinaev GP, Pitkin M. Skin and bone integrated prosthetic technology. II. Morphology and growth of cells on implants treated with different proteins [abstract]. In: Proceedings of the 9th Russian National Congress, People and Health. 2004 Nov 22-26; St. Petersburg, Russia; St. Petersburg: Russian National Congress; 2004. p. 205.

12. Galibin OV, Protasov MV, Chikhovskaya JV, Belyaeva IG, Pitkin M. Skin and bone integrated prosthetic technology. III. An exposed implantation of a porous titanium pellet into the skin [abstract]. In: Proceedings of the 9th Russian National Congress, People and Health. 2004 Nov 22-26; St. Petersburg, Russia; St. Petersburg: Russian National Congress; 2004. p. 210.

13. Pitkin M, Raykhtsaum G, inventors. Skin integrated device. United States patent application No.11/233,233. 2005. 
14. Likibi F, Assad M, Coillard C, Chabot G, Rivard CH. Bone integration and apposition of porous and non porous metallic orthopaedic biomaterials [French]. Ann Chir. 2005; 130(4):235-41. [PMID: 15847858]

15. Hubner E. Characterization of cells, microscopic. In: Spier RE, editor. Encyclopedia of cell technology. Hoboken (NJ): Wiley-Interscience; 2000. p. 551-77.

16. Blinova MI, Yudintseva NM, Kalmykova NV, Kuzminykh EV, Yurlova NA, Ovchinnikova OA, Potokin IL. Effect of melanins from black yeast fungi on proliferation and differentiation of cultivated human keratinocytes and fibroblasts. Cell Biol Int. 2003;27(2):135-46. [PMID: 12662970$]$

17. Ciolfi VJ, Pilliar R, McCulloch CS, Wang SX, Grynpas MD, Kandel RA. Chondrocyte interactions with porous titanium alloy and calcium polyphosphate substrates. Biomaterials. 2003;24(26):4761-70. [PMID: 14530073]

18. Cho SA, Jung SK. A removal torque of the laser-treated titanium implants in rabbit tibia. Biomaterials. 2003;24(26): 4859-63. [PMID: 14530083]
19. Fujibayashi S, Neo M, Kim HM, Kokubo T, Nakamura T. Osteoinduction of porous bioactive titanium metal. Biomaterials. 2003;25(3):443-50. [PMID: 14585692]

20. Kompala DS. Cell growth and protein expression kinetics. In: Spier RE, editor. Encyclopedia of cell technology. Hoboken (NJ): Wiley-Interscience; 2000. p. 383-92.

21. Butler M. Equipment and laboratory design for cell culture. In: Spier RE, editor. Encyclopedia of cell technology. Hoboken (NJ): Wiley-Interscience; 2000. p. 680-91.

22. Adams RL. Cell culture for biochemists. New York (NY): Elsevier; 1980.

23. Saltzman WM. Cell structure and motion, extracellular matrix and cell adhesion. In: Spier RE, editor. Encyclopedia of cell technology. Hoboken (NJ): Wiley-Interscience; 2000. p. 481-94.

Submitted for publication October 18, 2005. Accepted in revised form April 17, 2006. 